\title{
O QUEM DAS COISAS: ETNOGRAFIA E FEIIIC,ARIA EM LES MOTS, LA MORT, LES SORTS
}

\author{
Edgar Rodrigues Barbosa Neto \\ Universidade Federal de Minas Gerais - Brasil
}

\begin{abstract}
Resumo: Este artigo discorre sobre a relação entre a etnografia e a feitiçaria na obra Les mots, la mort, les sorts de Jeanne Favret-Saada. O seu objetivo inicial é apresentar os principais temas, e conceitos, propostos pela autora na descrição que faz da feitiçaria. Trata-se, nesse caso, de elaborar um comentário sobre o livro chamando a atenção para as inúmeras possibilidades que abre para uma "antropologia da feitiçaria". Destaco, entre muitas, o uso cuidadoso que a autora faz do que hoje chamaríamos de um "procedimento de equivalência" ou "princípio de simetria", a saber, do modo através do qual a etnografia e a feitiçaria, situadas em um mesmo "plano de imanência", descrevem-se mutuamente, dispondo-se em uma relação recíproca de transformação.
\end{abstract}

Palavras-chave: antropologia, etnografia, feitiçaria, Jeanne Favret-Saada.

Abstract: This article discusses the relationship between ethnography and witchcraft in Jeanne Favret-Saada's Les mots, la mort, les sorts (Deadly words). Its first aim is to present the main themes and concepts proposed by the author's description of witchcraft. As such, its purpose is to offer a commentary on the book by drawing attention to the various possibilities that it provides for an 'anthropology of witchcraft'.

* Agradeço a Marcio Goldman, Eduardo Viveiros de Castro, Paula de Siqueira Lopes e Cecília Campello do Amaral Mello pelos comentários feitos a uma versão preliminar deste texto. Agradeço também a Marina Vanzolini Figueiredo, com quem tenho conversado sobre muitos dos temas analisados neste artigo, e a Julia Sauma pela inestimável ajuda com o abstract. Observo que todas as passagens diretamente citadas do livro de Jeanne Favret-Saada serão mantidas na língua original, mas para cada uma delas o leitor poderá encontrar, na nota de rodapé, uma tradução livre. Sou grato a Isabella Mozzillo por tê-las cuidadosamente revisado. A edição que utilizo de Les mots, la mort, les sorts data de 1977, ano de sua primeira e, até onde sei, única publicação, integrada à coleção Folio/Essais da Gallimard (ver referências). Sempre que no corpo do texto aparecer uma citação sem menção à data, é a esse livro que ela se refere. Por uma economia estilística, para evitar uma cansativa redundância, decidi por essa elisão.

Horizontes Antropológicos, Porto Alegre, ano 18, n. 37, p. 235-260, jan./jun. 2012 
Among these, the article highlights the author's use of what we could call a 'procedure of equivalence' or 'principle of symmetry', namely the mode through which ethnography and witchcraft, when located on the same 'plane of immanence', can describe each other in a reciprocal relationship of transformation.

Keywords: anthropology, ethnography, Jeanne Favret-Saada, witchcraft.

Queria era que se achasse para ele o quem das coisas.

Guimarães Rosa

[...] comme une force anonyme, comme un 'ça'venu on ne sait d'où [...]

Jeanne Favret-Saada

\section{A feitiçaria e a etnografia}

"Ser afetado" é expressão que se encontra com certa frequência no discurso antropológico mais recente, em particular quando se trata de descrever o estilo de experiência implicado no trabalho de campo. Foi precisamente aí que Jeanne Favret-Saada concebeu essa noção, mas a sua circunscrição conceitual vai um pouco além, incluindo, ou mesmo reclamando, outras possibilidades, dentre as quais se destacam, nos termos dessa autora, uma "antropologia das terapias” e, mais amplamente, um "repensar a antropologia” (Favret-Saada, 2005, p. 155). É sobre essa segunda possibilidade que vou me deter no presente texto.

"Ser afetado" concerne a "uma dimensão central do trabalho de campo”, à experiência de habitar um "outro lugar”, de ser "tomado” pelas suas “intensidades específicas”, as quais, em geral, “não são significáveis” (FavretSaada, 2005, p. 155, 159). ${ }^{1}$ Não se trata, como já se escreveu, de entrar em uma relação fusional com as pessoas com as quais estudamos, nem de imaginar,

\footnotetext{
Trata-se daquilo que Goldman (2006, p. 16), aproximando criativamente o conceito de “devir” da noção de "ser afetado”, definiu como um “devir-nativo”. “Escrever”, dizia Deleuze (1997, p. 15), “não é certamente impor uma forma (de expressão) a uma matéria vivida [...] Escrever é um caso de devir [...] É um processo, ou seja, uma passagem de Vida que atravessa o vivível e o vivido. A escrita é inseparável do devir: ao escrever, estamos num devir-mulher, num devir-animal ou vegetal, num devir molécula, até num devir-imperceptível.” Ou ainda, acrescente-se, num devir-feiticeiro.
}

Horizontes Antropológicos, Porto Alegre, ano 18, n. 37, p. 235-260, jan./jun. 2012 
por um condescendente empatia, como seria estar no lugar delas, mas de efetivamente estar nesse lugar, de habitá-lo, ou de ser habitado por ele, não, novamente, por ter se tornado igual àqueles que o ocupam, e sim pelo fato de experimentar as intensidades que o constituem, as mesmas que virtualmente existem "comme une force anonyme, comme un 'ça' venu on ne sait d'où” (Favret-Saada, 1977, p. 311). ${ }^{2}$

A etnografia da feitiçaria, em Les mots, la mort, les sorts, começa no limite do seu próprio discurso, no confronto com a impossibilidade de descrever o que há para ser descrito, no ponto extremo onde o que escapa a ela, o seu "fora” como diriam Deleuze e Blanchot, dispõe-se internamente àquilo mesmo que a constitui. "Ser afetado", como algo que diz respeito à experiência de campo, conta pouco se não soubermos como transformá-lo, ou eventualmente traduzi-lo, ${ }^{3}$ em um experimento conceitual, se não soubermos, enfim, como extrair da rarefação do sentido, dessa força que excede à forma, um conceito e o mundo, ou os mundos, implicados nele. Les mots, la mort, les sorts supõe uma coextensividade conceitual entre os mundos projetados pela etnografia e pela feitiçaria, dispondo-os, de modo especialmente criativo, em uma relação de transformação recíproca, perfazendo, a seu modo, uma profunda demonstração daquilo que, desde Wagner (2010, p. 67), chamamos de "antropologia reversa”.

Goldman e Viveiros de Castro (2006, p. 186), referindo-se ao projeto antropológico de Marilyn Strathern, sugerem que ela soube tirar as consequências teóricas mais interessantes da questão que os pós-modernos levantaram, "mas com a qual não souberam lidar muito bem: como falar dos outros sem que se esteja falando de si mesmo". A resposta dada por ela, e que é também a deles, nos conduz a pensar que "mesmo que essa proeza seja impossível, isso não significa o silêncio - bem ao contrário do que supunham os próprios pósmodernos" (Goldman; Viveiros de Castro, 2006, p. 186). Tentarei demonstrar que Les mots, la mort, les sorts é um livro escrito precisamente neste lugar

\footnotetext{
“Como uma força anônima, como um ‘isso’ vindo sabe-se lá de onde.”

3 Tradução no sentido reivindicado por Otávio Velho (2001, p. 238, grifo do autor), a saber, como “uma via de mão dupla em que aquilo que é traduzido afeta a linguagem para a qual é traduzido e é afetado (tal como no caso do observador da mecânica quântica) pela tradução”. O presente texto persegue aliás uma ideia análoga àquela contida na pergunta “o que a religião pode fazer pelas ciências sociais?” Com efeito, o que a feitiçaria pode fazer pela etnografia ou ainda pela antropologia?
}

Horizontes Antropológicos, Porto Alegre, ano 18, n. 37, p. 235-260, jan./jun. 2012 
entre o impossível e o silêncio, na boa distância entre os dois, assentado sobre uma obstinada recusa de separar a alteridade da feitiçaria da sua capacidade de alteração da etnografia, supondo, portanto, que "os procedimentos que caracterizam a investigação são conceitualmente da mesma ordem que os procedimentos investigados” (Viveiros de Castro, 2002b, p. 117, grifo do autor).

O fato, note-se ainda, é que a conhecida crítica pós-moderna ao texto etnográfico como criador de uma representação descontextualizada dos mundos nativos, e sobretudo da experiência do antropólogo com esses mundos, já estava presente na sagaz observação de Favret-Saada segundo a qual a literatura etnográfica encontra-se fundada sobre a relação entre a não pessoa (o “on”) que escreve o texto e o sujeito indefinido (o "il” ou o "ils") a respeito do qual se fala no texto (p. 57). No entanto, mais importante do que isso, é observar que esse sistema de lugares (ou mesmo de não lugares) de que consiste a etnografia contrasta de modo fundamental com o sistema de lugares que é a feitiçaria: no primeiro, simplesmente não aparece qualquer contexto de enunciação, do que resulta uma certa atopia dos enunciados (eles são ditos, mas procedem de lugar nenhum, e ninguém, rigorosamente falando, os diz), ${ }^{4}$ no segundo, diferentemente, só há situação de enunciação, do que decorre uma tópica bastante estrita dos enunciados (o dito não é outra coisa senão quem o diz, para quem o diz e o lugar a partir do qual é dito). ${ }^{5}$

4 O contexto de enunciação só aparece deslocado do texto, seja no lugar da sua apresentação ou do seu prefácio, que é o momento em que se fala da experiência de campo, seja em outro livro, o qual, por isso, assume a forma de um diário ou de um relato, e no qual o discurso pode ganhar o tom de uma intimidade romanesca. Daí a pergunta irônica de Jeanne Favret-Saada: "Peut-on encore parler de science quand le texte, c'est son avant-propos?" ("Pode-se ainda falar de ciência quando o livro é o seu prefácio?”) (p. 54).

5 Os antropólogos dedicados ao estudo da feitiçaria tendiam a tomar o discurso nativo, como sugere Favret-Saada (2005, p. 156), apenas pelo seu efeito, desconectando o enunciado da atividade de sua enunciação, operação da qual resultava a sua transformação em uma proposição. A fala deixava, portanto, de ser uma ação, ou “um ato passível de ser observado", tornando-se um problema de representação, donde a sua ressonância com certos temas associados a uma "psicologia (ou mesmo sociologia) da crença”. Mas é importante notar que a recusa em separar os enunciados das suas situações de enunciação não significa que a feitiçaria seja transformada em uma pragmática sem qualquer conteúdo semântico, significa apenas, nesse caso, “levá-la a sério” (Goldman, 2006; Viveiros de Castro, 2002b), isto é, tomá-la em sua singular consistência conceitual, a fim de que se possa, a partir daí, extrair os efeitos teóricos mais relevantes para uma "antropologia da feitiçaria". Les mots, la mort, les sorts demonstra que o melhor ponto de partida para essa antropologia não diz respeito ao tratamento da feitiçaria como representação, mas à descrição do mundo que está implicado nela.

Horizontes Antropológicos, Porto Alegre, ano 18, n. 37, p. 235-260, jan./jun. 2012 
Pelo contraste, descobre-se que a feitiçaria pode funcionar como uma crítica etnográfica, isto é, feiticeira, da própria etnografia, e, logo, como uma das formas de contornar os seus impasses enunciativos. Mas se isso de fato é assim, é porque, de outro modo, a criação etnográfica não pode ser resumida a um problema de representação. "Ser afetado" é o nome que Favret-Saada escolheu dar a essa experiência de criação que escapa à representação, uma experiência que é simultaneamente de campo e de texto, e, sobretudo, de sua sutil e delicada conexão.

Les mots, la mort, les sorts está montado em três grandes partes. A primeira, intitulada “Qu’il faut, au moins, un sujet” (“Que é necessário, ao menos, um sujeito”), situa a pesquisa e apresenta o tratamento etnográfico que será concedido ao tema, enquanto as duas últimas, respectivamente "L'Empire du secret” (“O império do segredo”) e “Tout dire” (“Tudo dizer”), esta a mais extensa do livro, são dedicadas à descrição das várias histórias de feitiçaria que constituem a matéria principal da etnografia. A pesquisa de campo foi conduzida entre 1968 e 1971, ao passo que a escrita e a publicação acontecem apenas em 1977.

Elaborado e escrito em uma época (não tão distante assim) em que a imagem do pensamento dominante na academia ainda não era construída pelos parâmetros empresariais capitalistas da rentabilidade e da produtividade, o livro levou quase dez anos para ficar pronto. (Goldman, 2005, p. 149).

Esse tempo, como observa Goldman, não é externo à construção do texto, antes pelo contrário, já que foi apenas depois de praticamente um ano, após a autora ter sido ela própria diagnosticada como enfeitiçada, que as pessoas passaram a conversar com ela sobre feitiçaria. Precisamente por isso, o tempo de pesquisa é intrínseco à matéria etnográfica. Inteiramente consagrado à feitiçaria, cuidadosamente descrita como um "sistema de lugares”, o livro contém uma reflexão profunda sobre a própria maneira de descrever o tema de que trata. A etnografia da feitiçaria é também uma meditação feiticeira sobre a etnografia, e, mais amplamente, sobre os modos de conceituar essa relação. É precisamente isso que faz do livro um importantíssimo lugar para pensar certas questões transversais ao debate antropológico contemporâneo. 


\section{A feiticaria afeta a etnografia}

"Soit une ethnographe: elle a choisi d'enquêter sur la sorcellerie dans le Bocage de l'Ouest.” (p. 15). Eis a frase que abre o livro. Suponha então uma etnógrafa: ela. "Ela”, parece óbvio, é a autora, mas daí não se segue que essa escolha narrativa inicial obedeça a uma bastante improvável gratuidade estilística. Pois não será significativo que se comece na terceira pessoa um livro que é inteiramente escrito na primeira pessoa? Essa pergunta rende uma outra: se a etnógrafa é posta na condição de “ela”, então o "eu” que narra as diversas histórias de feitiçaria que compõem o livro é quem? Encadeie-se ainda a essas duas uma última questão: se a terceira pessoa (que é, conforme demonstrou Benveniste (1988), uma “não pessoa”) é o "lugar” daquele “sujeito indefinido” tradicionalmente reservado pela etnografia aos nativos, então o que faz a etnógrafa nesse "lugar”? O que segue abaixo é uma tentativa de respondê-las.

Sugiro, para começar, o seguinte: se a etnógrafa principia por uma referência a si mesma na terceira pessoa, é porque não há lugar para ela na experiência de campo que tornou possível a existência do livro que lhe coube escrever. "Ela” é o pronome que condensa o vazio desse lugar a partir do qual a etnografia foi escrita. Vejamos o que isso quer dizer.

Desde o início de seu trabalho de campo, Favret-Saada constata que nada do que concerne à feitiçaria se presta a uma descrição etnográfica nos moldes tradicionais. O único fato empírico que há para se descrever é a fala. Mas o caso é que a fala, por sua vez, jamais ocorre como processo desinteressado, isto é, está rigorosamente fora de questão tratá-la como um veículo de informação ou de saber. Alguém que queira apenas saber por saber, não terá lugar, ou parecerá um ingênuo.

Parler de sorcellerie, ce n'y est jamais pour savoir, mais pour pouvoir [...] Avant qu'il n'ait prononcé un mot, l'ethnographe est inscrit dans un rapport de forces, au même titre que quiconque prétend parler. Qu'il parle, et son interlocuteur

\footnotetext{
6 “Suponha uma etnográfa: ela escolheu pesquisar a feitiçaria no Bocage ocidental.” Bocage (termo que pode ser literalmente traduzido como "mata”) é um nome usado para designar, na França, determinadas regiões rurais. Jeanne Favret-Saada optou por não fornecer a localização exata do lugar no qual realizou a sua pesquisa, sabemos apenas que se trata do Bocage normando, situado no limite ocidental da Baixa Normandia.
}

Horizontes Antropológicos, Porto Alegre, ano 18, n. 37, p. 235-260, jan./jun. 2012 
cherche avant tout à identifier sa stratégie, à mesurer sa force, à deviner s’il est ami ou ennemi, s’il faut l'acheter ou le détruire. (p. 28). ${ }^{7}$

É porque a “fala é uma guerra” que as informações sobre a feitiçaria têm a particularidade de não serem propriamente informações, e sim momentos em uma estratégia. $\mathrm{O}$ que chamamos de informação não é senão a expressão de um desses momentos: a fala é o lugar e quem o ocupa. ${ }^{8}$ Daí porque falar sobre a feitiçaria é sempre perigoso. ${ }^{9}$ Em um tal contexto, o etnógrafo só pode ser um falante como qualquer outro, sujeito às mesmas forças ou intensidades feiticeiras. Mantendo-se etnógrafo, preservando a sua posição de observador, de atopos, não haveria etnografia para escrever.

A feitiçaria, portanto, não é observável, tanto quanto não é dizível. Ou melhor, só se pode vê-la ao dizê-la, e dizê-la já é, de algum modo, fazê-la. Em outras palavras, não pode haver observação porque, nesse sistema de lugares que é a feitiçaria, não há lugar para o que não tem lugar. “Autant dire qu’il n’y a pas de position neutre de la parole: en sorcellerie, la parole, c'est la guerre. Quiconque en parle est un belligérant et l'ethnographe comme tout le monde. Il n’y a pas de place pour un observateur non engagé.” (p. 27). ${ }^{10}$ A ideia de um saber intransitivo, de um saber que contenha no próprio ato de saber a sua razão de existir, não tem relevância na “epistemologia da feitiçaria”. Vê-se que a guerra sobre a qual se funda esse sistema neutraliza o uso representativo da fala e do conhecimento.

No entanto, avançando um pouco, observa-se que pode sim haver um lugar para o etnógrafo. Qual seja? O mesmo que aquele reservado para outros personagens como os médicos, os jornalistas... e todos os demais que, por não terem sido tomados pela feitiçaria, não podem saber do que se trata. Quem nunca passou por uma experiência desse tipo não pode realmente entender

\footnotetext{
7 “Jamais se fala de feitiçaria para saber, mas para poder [...] Antes que tenha pronunciado uma palavra, o etnógrafo encontra-se inscrito em uma relação de forças, do mesmo modo que qualquer um que pretenda falar. Ele fala, e seu interlocutor busca, antes de tudo, identificar sua estratégia, medir sua força, avaliar se é amigo ou inimigo, se é necessário comprá-lo ou destruí-lo.”

8 “[...] rien n’est étranger à la socellerie qu'une relation d’information” (“nada é mais estranho à feitiçaria do que uma relação de informação”) (p. 286).

9 Esse perigo acha-se marcado pela expressão: “moins on en parle, moins on y est pris” (algo como: “[quanto] menos se fala [sobre a feitiçaria] menos se é tomado [por ela]”).

10 “Em outras palavras, não há posição neutra para a fala: na feitiçaria, a fala é a guerra. Quem quer que fale é um beligerante, e o etnógrafo é como todo mundo. Não há lugar para um observador não engajado.”
} 
o que acontece, ou, para dizer de outro modo, só pode achar que se trata da credulidade de camponeses ingênuos. Com tais personagens, só há então duas possibilidades: ou o silêncio, ou a denegação ("a feitiçaria de fato não existe”, “é coisa dos antigos, dos loucos e dos ingênuos”). É aqui que nos deparamos com um problema fundamental posto por esse livro: o uso da noção de crença e a ambiguidade a ela associada. ${ }^{11}$

Note-se que a posição desse outro que diz que a feitiçaria é coisa dos crédulos e ingênuos é ela própria imanente ao sistema da feitiçaria. A rigor, ninguém acredita na feitiçaria, e se acredita é porque é um tolo. Como alguém poderia acreditar na feitiçaria se nunca passou por essa experiência, se nunca foi tomado por ela? "Ninguém acredita na feitiçaria”, quer dizer, "ninguém acredita nela por princípio”. O próprio enfeitiçado define como supersticioso aquele que acredita, por princípio, na feitiçaria, isto é, aquele para quem ela existiria absolutamente. Mas o caso é que a feitiçaria não existe antes do seu acontecimento para alguém.

Que a feitiçaria seja posta sob a forma do evento e da experiência é algo que deve reter, momentaneamente, a nossa atenção. Basta lembrar que no clássico ensaio de Mauss e Hubert (2003) era isso que lhe era negado (uma negação, acrescente-se, que fez alguma história na antropologia). Dizem eles:

[...] a experiência sensível jamais forneceu a prova de um juízo mágico; a realidade objetiva jamais impôs ao espírito nenhuma proposição do gênero das que formulamos mais acima. É evidente que nunca se viu, a não ser com os olhos da fé, um corpo astral, uma fumaça que faz chover e, com mais forte razão, um espírito invisível que obedece a um rito. (Mauss; Hubert, 2003, p. 156).

Essa observação é notável porque torna evidente o modo como a noção de crença pode produzir um efeito desrealizante sobre o mundo (Latour, 1996). No idioma kantiano em que esse texto foi escrito, uma tal observação significava que “os juízos mágicos” deveriam ser entendidos como “juízos sintéticos a priori”, o que implicava, de outra maneira, a suposição de que a

11 Marie Fourmond, cujo pai, supõe-se, teria morrido vítima de um feitiço, diz para Favret-Saada (1977, p. 91): “J’y croyais pas tellement encore, mais j’ai dit à l’homme de Quelaines: Vous savez qui c'est?” ("Eu ainda não acreditava suficientemente [que meu pai estivesse enfeitiçado], mas perguntei ao homem de Quelaines: você sabe quem é? [o feiticeiro de meu pai].”)

Horizontes Antropológicos, Porto Alegre, ano 18, n. 37, p. 235-260, jan./jun. 2012 
crença na magia (e em particular na sua eficácia) fosse anterior à experiência mágica, e que, no limite, só aquela crença pudesse existir.

Se, como dizia Boas, “o olho que vê é um órgão da tradição”, então “os olhos da fé” evocados acima são um órgão de um “consenso coletivo”, de um poderoso investimento social, disso que, diferentemente da magia, realmente existe. Como se vê, ela só seria explicável à condição de uma redução de sua singularidade ontológica, a saber, tornando-a um fenômeno puramente derivado. Veremos que esse kantismo sociológico contém mais do que um problema teórico.

Certamente se deve questionar a noção de crença como essa noção insidiosa que permite que se joguem as pessoas para o campo da pura representação. Melhor do que isso, contudo, talvez seja descrever a maneira como essas próprias pessoas se utilizam dessa noção para contornar o efeito de desrealização do seu mundo. Antes de Latour (1996), já havia alguém do Bocage interessado nesse problema.

O que uma pessoa faz quando alguém diz que o seu mundo é um efeito da sua crença, isto é, que no fundo ele não existe? ${ }^{12}$ Penso que a resposta dos habitantes do Bocage é a seguinte: de fato, a feitiçaria não existe, é realmente coisa dos crédulos, mais quand même... "Mas mesmo assim" é a expressão que se pode encontrar na fala de todos os enfeitiçados do livro, na da etnógrafa inclusive (Mannoni, 1991). Compare-se o que diz Marie Fourmond sobre o enfeitiçamento de seu pai com o que diz Jeanne Favret-Saada sobre o feitiço que, conforme lhe disseram, foi jogado sobre ela: "Je sais bien que 'le cancer, c'est le cancer', s'est dit, en substance, Marie Fournond - soit, qu'on se meurt - mais quand même, si le 'toucheur' pouvait sauver mon père...” (p. 95, grifo da autora). ${ }^{13}$ Diz agora a autora:

Je sais bien que celui qu'on dit être mon sorcier n’a jamais pratiqué la moindre magie contre moi; je sais bien que les rituels de madame Flora, par eux-mêmes,

12 Recorde-se que essa era a questão principal do belíssimo livro $A$ invenção do cotidiano de Michel de Certeau (2005): o que as pessoas fazem com aquilo que fazem com elas? Certamente não por acaso, essa mesma questão já se encontrava prefigurada na sua descrição da "palavra da possuída”, no modo como essa palavra desestabilizava o discurso demonológico utilizando-se dos lugares desse próprio discurso (De Certeau, 2006).

13 “Sei bem que o 'câncer é o câncer', diz a si mesma, com efeito, Marie Fournond - ou seja, que a gente morre - mas mesmo assim, se o ‘tocador’ pudesse salvar o meu pai...” 
ne peuvent provoquer quelque effet que ce soit: ni contre la sorcière de Joséphine, ni contre mon sorcier; mais quand même puisque tant de voeux de mort circulent en tous sens...vais-je mourir, à mon tour, dans un accident de voiture? (p. 217, grifo da autora). ${ }^{14}$

"Eu sei bem [que não estou enfeitiçada]... mas mesmo assim... posto que tantos desejos de morte circulam em todas as direções, será que vou morrer [...] em um acidente de carro?”"15 $\mathrm{O}$ que está implicado nessa fórmula tão precisa, e, ao mesmo tempo, tão suficientemente aberta para recobrir diferentes significados, é o fato de que a feitiçaria é um problema de quando e de onde, tratando-se assim de algo cuja existência está em estrita relação com a circunstância de seu acontecimento. Tendo isso em vista, deve-se interpretar com certa cautela a seguinte observação:

[C]e qui importe à l'indigène, c'est que celui qui l'écoute - soit l'ethnographe, qui nécessairement participe du langage objectiviste - ne puisse le reconnaître dans ce qu'il énonce. Il ne parle de la sorcellerie qu'à la condition de s'en distinguer et, par conséquent, de la présenter comme une construction particulièrment infantile, abracadabrante et ridicule. (p. 36). ${ }^{16}$

O que importa ao nativo é impedir que aquele que o escuta - como, por exemplo, o etnógrafo - o reconheça naquilo que ele próprio enuncia. Mas não acho que se possa deduzir daí que esse nativo esteja apenas, como se diz, "manipulando”. Quando se afirma que a feitiçaria não existe, não creio, portanto, que se esteja dizendo ou pensando uma outra coisa por trás daquilo mesmo que se diz, como se estivéssemos diante de algo do tipo "sei que existe, mas direi que não existe porque é isso que se quer ouvir”.

14 “Eu sei bem que aquele que dizem ser meu feiticeiro jamais praticou a menor magia contra mim; sei bem que os rituais da senhora Flora, por si sós, não podem provocar qualquer efeito: nem contra a feiticeira de Joséphine, nem contra o meu feiticeiro; mas mesmo assim, posto que tantos desejos de morte circulam em todas as direções, será que vou morrer, quando chegar a minha vez, em um acidente de carro?”

15 De fato, “que l'ethnographe qui n'a jamais somatisé me jette la première pierre” (“que jogue a primeira pedra o etnógrafo que nunca somatizou”) (p. 113).

16 "O que interessa ao nativo é que aquele que o escuta - como o etnógrafo que necessariamente participa da linguagem objetivista - não possa reconhecê-lo naquilo que ele enuncia. Ele só fala de feitiçaria com a condição de se distinguir dela e, por conseguinte, de apresentá-la como uma construção infantil, mágica e ridícula."

Horizontes Antropológicos, Porto Alegre, ano 18, n. 37, p. 235-260, jan./jun. 2012 
Se a feitiçaria é um sistema de lugares ao qual se associa um belicoso e delicado sistema de atos de fala, então esse lugar (o necessário lugar do crédulo, tal como o descreve o capítulo IV do livro) se define por uma fala que é uma espécie de duplo silencioso de todas as outras: "aqui eu não falo aquilo que eu falo lá”. Insisto que isso não se deve ao fato de que, em um lugar, se esteja fingindo ou omitindo, enquanto em outro, não. E sim porque, aqui, a feitiçaria não existe, e lá, ela existe. Em outras palavras, a feitiçaria não existe a não ser quando existe.

Mas à medida que ela passa a existir, aí então parece ser conveniente acreditar nela. Quando o desenfeitiçamento do pai de Marie Fourmond falhou, o seu desenfeitiçador, o homem de Quelaines, atribuiu o fracasso à pouca crença dos interessados. Em contrapartida, o restante da comunidade acusavaos de profunda credulidade. Para uns, acreditava-se de mais, para outro, de menos, e para aqueles diretamente envolvidos, era sempre mais ou menos.

"Qu'il faut, au moins, un crédule”. ${ }^{17}$ Mas não apenas para que se faça do discurso sobre esse crédulo um esconderijo da feitiçaria. Diferentemente, sugiro que isso é assim para que se possa falar com o outro como outro. Sobre a feitiçaria, o habitante do Bocage fala com o outro (quem quer que não tenha sido tomado por ela) como esse outro fala com ele (p. 80). Desde que o etnógrafo permaneça aí, só poderá ouvir essa fala, a qual, de resto, não seria a sua própria voz?

“Le premier point à elucider, quand on fait l'ethnographie des sorts, c'est donc de savoir à qui chaque 'informateur' croit s'adresser, puisqu'il tient des discours si radicalement différents selon la place où il situe son interlocuteur.” (p. 36) ${ }^{18}$ Questão delicada e decisiva que se coloca para o etnógrafo em campo: quando alguém fala comigo com quem essa pessoa está exatamente falando? Se é como etnógrafo que converso com ela, não é como etnógrafo que ela me vê ao conversar comigo. Em se tratando da feitiçaria, que eu não seja visto como tal é a condição para que essa pessoa me dirija a palavra. “Comme à n'importe quel locuteur, c’est à un sujet supposé pouvoir (un sorcier, un désenvoûteur) ou ne pas pouvoir (une victime, un ensorcelé) qu’on s'adresse

17 "Que é necessário, pelo menos, um crédulo."

18 "Quando se trata de uma etnografia dos sortilégios [da feitiçaria], o primeiro ponto a elucidar é, portanto, aquele de saber a quem cada 'informante’ acredita se dirigir, já que ele dispõe de discursos muito diferentes segundo o lugar onde situa o seu interlocutor.”

Horizontes Antropológicos, Porto Alegre, ano 18, n. 37, p. 235-260, jan./jun. 2012 
lorsqu’on parle à l’ethnographe.” (p. 29, grifo da autora). ${ }^{19}$ Só há etnografia porque não há, por assim dizer, etnógrafo.

O percurso de Favret-Saada em campo pode ser sintetizado na progressiva compreensão de uma única ideia e de suas profundas consequências: não há nada que se diga sobre a feitiçaria que não seja estreitamente comandado pela situação de enunciação. O que importa, portanto, é menos decifrar enunciados - ou aquilo que é dito - do que compreender quem fala, e a quem dirige essa sua fala. ${ }^{20}$

Uma outra importante particularidade desse sistema é que a iniciativa discursiva cabe sempre a um terceiro: nenhuma pessoa se diz feiticeira, tanto quanto ninguém se reconhece e identifica como enfeitiçado (p. 38). No primeiro caso, é o desenfeitiçador quem diz o nome do feiticeiro, já no segundo, quem diz que se está enfeitiçado é o anunciador. ${ }^{21}$ Assim, como não poderia deixar ser, foram os interlocutores de Jeanne Favret-Saada que lhe designaram o seu lugar, e o fizeram interpretando os signos, para ela involuntários, que o seu discurso, e também a sua aparência e certos eventos de sua vida, oferecia para eles. Situando-a como enfeitiçada e como desenfeitiçadora, falaram com ela sobre a feitiçaria.

Se não há nada que possa ser dito sobre a feitiçaria que não seja comandado pela situação de enunciação, o que dizer da etnografia feita sobre ela? Precisamente isso: os enunciados etnográficos trazem consigo a sua situação não etnográfica de enunciação. Favret-Saada conta que o diário que escrevia cotidianamente em campo era o que lhe permitia imaginar, ainda que não sem hesitações, que tudo aquilo que acontecia com ela poderia algum dia virar uma outra coisa. "Quoi qu'il arrivât, je partageais mon temps entre les entretiens et la redaction de ces notes; je m’y donnai pour règle d'y inscrire moins mes

19 "Não importa qual o interlocutor: é a um sujeito supostamente poderoso (um feiticeiro, um desenfeitiçador) ou a um sujeito destituído de poder (uma vítima, um enfeitiçado) que alguém se dirige quando fala com o etnógrafo."

${ }^{20}$ Como já sugeri anteriormente, há situações em que uma descrição semântica desses enunciados se faz mais necessária, em particular, mas não exclusivamente, naqueles casos em que "o feiticeiro não é o outro” e onde a feitiçaria pode incluir um vasto e complicado conjunto de objetos, animais, técnicas rituais, materiais sensíveis, etc. Os materiais feiticeiros de Favret-Saada apresentam uma forma minimalista se comparados, por exemplo, com aqueles que podem ser encontrados entre as religiões afro-brasileiras (Barbosa Neto, 2012).

21 Trata-se de alguém que, tendo sido curado de seus males, anuncia para uma pessoa que ela está enfeitiçada.

Horizontes Antropológicos, Porto Alegre, ano 18, n. 37, p. 235-260, jan./jun. 2012 
états d'âme que le discours indigène en y incluant les silences, les lapsus, les retours en arrière, les césures, etc” (p. 254). ${ }^{22} \mathrm{O}$ diário são essas notas que funcionam como o anúncio de um "livro por vir", mas ao qual só se chega, se é que se chega, por esse retorno ao campo que é a volta do campo sobre o livro. ${ }^{23} \mathrm{~A}$ etnografia é o nome desse retorno, o diário tornando-se a dobra, de tempo e espaço, que o faz existir.

Foi porque as pessoas colocaram a etnógrafa à distância da prática etnográfica que uma etnografia da feitiçaria pôde ser escrita. O pronome "ela", para voltarmos ao começo, é a marca textual dessa distância; o pronome "eu", a sua interiorização na voz da etnógrafa. ${ }^{24}$ Dizer assim que o livro é escrito na primeira pessoa parece insuficiente: o "eu" que narra só o faz por assumir, no texto etnográfico, a existência topológica de sua experiência heteronímica de campo. ${ }^{25}$ A primeira pessoa não é sempre a mesma pessoa. ${ }^{26}$

De fato, a alternativa à atopia do sujeito teórico dificilmente poderia ser a assunção subjetiva de um “eu” ${ }^{27}$ No livro, aquela existência topológica

22 "O que quer que acontecesse, eu dividia o meu tempo entre as conversas e a redação destas notas; estabeleci como regra descrever menos os meus estados de espírito do que o discurso nativo, incluindo aí os seus silêncios, os seus lapsos, os seus flashbacks, os seus eufemismos, etc."

23 "S'il s'avise ensuite de rédiger un mémoire scientifique sur les sorts, ce ne peut se faire qu'en revenant toujours sur cette situation d'énonciation et sur la manière dont il y a été 'pris'; faisant, de ce mouvement de va-et-vient entre la 'prise' initiale et sa 'reprise' théorique, l'objet même de sa réflexion." ("Tratando-se em seguida de redigir um relato científico a respeito dos sortilégios, não se pode fazê-lo senão retornando a essa situação de enunciação e à maneira pela qual se foi tomado por ela, fazendo, desse movimento de vaivém entre a 'tomada' inicial e a sua 'retomada' teórica, o próprio objeto de sua reflexão.”) (p. 33, grifo da autora).

24 "O ego está lá, mas só para dizer que se retira, se expulsa da consciência plena, que se conduz ao extremo de si mesmo, lá onde se dissolve no momento: subjetivo, individual é o momento, não é o sujeito, o indivíduo.” (Barthes, 2004, p. 223, grifo do autor).

25 "J'entends ainsi marquer sans équivoque la distance qui me sépare de l'anthropologie classique comme de la pensée post-structurale en France, dans leur commun idéal de totale a-topie du sujet théoricien.” ("Pretendo assim deixar clara a distância que me separa da antropologia clássica tanto quanto do pensamento pós-estrutural francês, em seu ideal compartilhado de uma total a-topia do sujeito teórico.”) (p. 33). Uma comparação sistemática com os heterônimos pessoanos poderia revelar toda uma outra maneira de conceber a experiência do antropológo em campo, e do modo como, na sequencia, o campo se transforma em texto.

26 'Dissemos que 'Eu denota quem emite o enunciado’ é uma instrução insuficiente para identificar o referente, visto que ele muda conforme o contexto e a circunstância, e portanto não representa o conteúdo do pronome Eu.” (Eco, 1998, p. 279, grifo do autor).

${ }^{27}$ Lê-se algo parecido em Michel Leiris (2007, p. 300): “[...] é pela subjetividade (levada a seu paroxismo) que se alcança a objetividade”. Mas as semelhanças não podem ir muito longe, já que o caminho de Jeanne Favret-Saada parece traçar uma diagonal entre a subjetividade e a objetividade.

Horizontes Antropológicos, Porto Alegre, ano 18, n. 37, p. 235-260, jan./jun. 2012 
assume uma forma diretamente narrativa: dado que a feitiçaria é apenas fala, e uma fala da qual só se pode participar com a condição de se estar inteiramente implicado nela, caberá à etnógrafa a tarefa de contar as histórias que lhe contaram porque ela não era etnógrafa. Quem fala sobre a feitiçaria é porque, por assim dizer, foi falado por ela. Les mots, la mort, les sorts é um livro inteiramente falado pela feitiçaria, a saber, uma etnografia na qual a etnógrafa só pode dizer a feitiçaria, dizendo, a partir das histórias que conta, o modo como foi dita por ela. O etnógrafo é dito como outro que não etnógrafo no interior mesmo daquilo que diz, e só por isso pode dizer etnograficamente o que diz.

\section{A etnografia descreve a feitiçaria}

“Ela”, portanto, é a etnógrafa, aquela cujo lugar é o lugar que um outro lhe deu, o lugar a partir do qual a etnografia é possível. Ela, a etnógrafa, ocupou todos os lugares do discurso sobre a feitiçaria (p. 49), permitindo-se assim divisar o conjunto do enunciável, à exceção daquele que, como o dela, também só existe para um outro: o lugar do feiticeiro. No Bocage, não há quem se assuma como tal. É sempre um outro, o enfeitiçado ou o desenfeitiçador, ou ambos, e mesmo eventualmente o anunciador, quem diz de alguém que ele é feiticeiro. Não será casual, portanto, que o feiticeiro também seja “ele”, aquele cujo lugar é o lugar que um outro lhe dá, o lugar a partir do qual a feitiçaria é possível.

A etnógrafa e o feiticeiro são esses dois outros que nunca se encontram, a não ser pelo fato de que ambos só podem existir pelos outros. Suponho que seja isso o que a prática da etnografia e a prática da feitiçaria têm em comum. Mais ainda, sugiro que a disjunção entre o etnógrafo e o feiticeiro possa ter alguma relação com a conjunção entre a etnografia e a feitiçaria. De alguma forma, o encontro entre essas duas é feito do desencontro entre os dois primeiros.

Entretanto, a relação entre o etnógrafo e sua etnografia não é simétrica à relação entre o feiticeiro e sua magia. Enquanto o etnógrafo escreve sua etnografia ao ser dito, por um outro, como sendo outro que não etnógrafo, o feiticeiro permanece como esse outro que nunca assume a palavra do outro como condição para enunciar a sua, isto é, ele jamais admite praticar a sua magia. O etnógrafo é quem fala por ser falado, mas o feiticeiro é o contrário: é precisamente aquele que não fala por ser falado, e quando fala é só para dizerse outro que não feiticeiro.

Horizontes Antropológicos, Porto Alegre, ano 18, n. 37, p. 235-260, jan./jun. 2012 
Para o primeiro, ser falado é a condição para que haja discurso, para o segundo, é a própria impossibilidade desse discurso, o silêncio que constantemente o envia para um lugar que, como veremos, oscila entre o vazio e o excesso. Quem é então o feiticeiro? O feiticeiro é aquele, por hipótese qualquer um, que nunca é, para si mesmo, o feiticeiro. O que estou sugerindo, enfim, é que se entenda a passagem entre aquelas duas relações (a do etnógrafo e sua etnografia, a do feiticeiro e sua magia) como resultante da mediação criada por uma transformação.

Se o lugar do etnógrafo é o lugar dos outros, então o lugar do feiticeiro, para o etnógrafo, é esse lugar que é sempre outro para os outros. O etnógrafo diz esse outro dizendo-o como os outros o dizem. Tudo o que se pode saber sobre o feiticeiro como feiticeiro não vem dele. O restante deste texto é dedicado a examinar o que pode estar implicado nesse saber.

Desde que a feitiçaria é aquilo que se expressa em um acontecimento, e não sob a forma dessa adesão incondicional (ou quase isso) a que chamamos de princípio, quando então se pode dizer que ela existe? Quando se é tomado pela repetição do infortúnio: a praga na plantação, o animal que morre, a vaca que não dá leite, o carro que estraga, a impotência sexual de um filho... Que uma dessas coisas aconteça, não está bom, mas é algo esperado. Contudo, desde que ela ganhe forma no interior de infortúnios que, um após o outro, se repetem, então algo está muito mal, e é razoável que se comece a suspeitar de que um outro processo esteja em curso.

Ninguém, entretanto, dirá de si mesmo que está enfeitiçado. Uma terceira pessoa, "car, en sorcellerie, il faut toujours un médiateur pour la parole du sujet” (p. 110), se encarregará de fazê-lo. ${ }^{28}$ A palavra desse terceiro faz advir o evento-feitiçaria. A partir daí, desenrola-se um longo processo, do qual é parte necessária a definição do nome do feiticeiro, e cujo final será o enfrentamento corpo a corpo, mas sem contato físico direto, entre, de um lado, o enfeitiçado e o desenfeitiçador e, de outro, o feiticeiro. A observação de Goldman (2005, p. 152) sugere que se trata

[...] de um conflito ou de uma oposição (entre feiticeiro e enfeitiçado), devidamente sistematizada e, em geral, resolvida pela intervenção de uma terceira instância, o desenfeitiçador, que, no entanto, não aparece como externa e acima das

28 “Pois, na feitiçaria, é sempre necessário um mediador para a palavra do sujeito.” 
demais (como ocorreria com uma regulação estatal ou médica de conflitos ou perturbações), e sim como um aliado e um duplo da vítima contra seu inimigo.

Parece especialmente importante essa ideia de uma terceira posição imanente às duas que se encontram em guerra, e pretendo retomá-la mais adiante. Mas volto agora ao que dizia antes para sugerir que o acontecimento da feitiçaria no Bocage pode ser observado, pelo menos no que se refere aos seus efeitos iniciais, como uma inversão daquele que se encontra entre os azandes. Referindo-se ao rapaz que deu uma topada em um toco de árvore, Evans-Pritchard (2005, p. 52) observa que "o que ele atribuiu à feitiçaria foi que, nessa ocasião em particular, enquanto exercia sua cautela costumeira, ele bateu com o pé em um toco de árvore, ao passo que em centenas de outras ocasiões isso não acontecera [...]”. Tendo em vista que ele sempre caminhava com segurança por aquele lugar, por qual razão, naquela particular circunstância, teria machucado o pé?

Enquanto no Bocage o evento-feitiçaria equivale a uma repetição, entre os azandes o que parece contar é exatamente o que escapa à repetição. Mas essa diferença não é absoluta, e mesmo no Bocage é possível encontrar, por ocasião da confirmação do nome do feiticeiro, a presença atestatória do particular. Foi esse o caso daquele vizinho que nunca cumprimentava o enfeitiçado, até que, num certo dia, seguramente movido pela pior das intenções, teria se dedicado a fazê-lo de tal forma esfuziante que só poderia mesmo levantar terríveis suspeitas sobre o sentido do seu ato. ${ }^{29}$ Paula de Siqueira Lopes, que estuda feitiçaria no baixo sul baiano, sugeriu, em comunicação pessoal, que no Bocage estaríamos diante de uma "repetição do que escapa à repetição: o leite que nunca azeda, mas azedou; a manteiga que nunca talha, mas talhou; a vaca sempre cheia de leite, mas que secou”. Parece-me perfeita essa sua observação. Uma coisa que nunca acontece, aconteceu. O problema, de fato, é quando duas ou mais coisas que nunca acontecem, começam a acontecer, daí, justamente, a repetição. O evento-feitiçaria talvez seja iniciado quando a diferença introduzida em uma série marcada por um certo tipo de repetição se conecta com a repetição dessa diferença entre as várias séries que até então pertenciam a casos descontínuos.

${ }^{29}$ Há três formas pelas quais o feiticeiro pode agir: pelo toque, pela fala e pelo olhar. 
De todo modo, em se tratando da feitiçaria como repetição, a causa do infortúnio jamais coincide com a sua origem. ${ }^{30}$ Enquanto a primeira pode ser facilmente acomodada a uma resposta com base em um conhecimento positivo, algo do tipo "a vaca não dá leite porque está sofrendo de algum problema hormonal”, ou "a praga na plantação se deve ao uso imprudente de algum veneno", etc., a segunda supõe a presença ativa de uma pessoa. Esse fenômeno, razoavelmente bem conhecido, é em tudo análogo àquele do xamanismo amazônico: “[...] a boa interpretação xamânica é aquela que consegue ver cada evento como sendo, em verdade, uma ação, uma expressão de estados ou predicados intencionais de algum agente" (Viveiros de Castro, 2002a, p. 359, grifo do autor). No Bocage, é a diferença interna à repetição, associada, como disse antes, à sua repetição entre séries diferentes, as quais, precisamente por isso, se tornam contínuas, que faz ver o evento como uma ação.

Para o saber médico, cada caso tende a ser sempre um caso, o problema da vaca não sendo o mesmo que o da plantação, e nenhum desses dois, por sua vez, sendo igual àquele da impotência de um indivíduo. No entanto, porque durante o evento-feitiçaria não pode haver separação, qualquer ideia como essa de separar para melhor curar é rechaçada. Se o ataque é sempre dirigido ao chefe da família, os seus efeitos se estendem para além dos seus limites individuais, podendo incidir sobre a sua mulher, os seus filhos, os seus animais, as suas posses materiais..., os quais formam com ele, por compartilharem do seu nome, um corpo único, uma única superfície. ${ }^{31}$ É até mesmo possível que um homem seja enfeitiçado sem que nada lhe aconteça diretamente (p. 218).

O evento-feitiçaria supõe o indivíduo como uma "pessoa distribuída" (Gell, 1998), sendo o seu nome (que, como disse, se estende sobre todo o seu

\footnotetext{
30 'Puisqu'il s'agit des sorts, la cause première de toute mort, même naturelle, ne saurait être trouvée que dans le désir d'un sorcier, désir nécessairement plus fort que celui de la défunte [refere-se ao caso de uma enfeitiçada que morreu]." ("Tratando-se de sortilégios, a causa primeira de toda morte, mesmo aquela natural, só saberia ser encontrada no desejo de um feiticeiro, desejo necessariamente mais forte do que aquele da defunta.”) (p. 290). Note-se que nessa passagem Favret-Saada, seguindo a terminologia de Evans-Pritchard (que falava de causa primária ou primeira e causa secundária), chama a "origem" de "causa primeira".

31 "Cette surface unique dont tous les points sont solidaires, convenons de la désigner comme l'ensemble défini par le nom du chef de famille et les points qui la constituent comme ses éléments." ("Esta superfície única na qual todos os pontos são solidários, convencionamos designá-la como o conjunto definido pelo nome do chefe de família, e como elementos esses pontos que o constituem.”) (p. 218, grifo da autora).
}

Horizontes Antropológicos, Porto Alegre, ano 18, n. 37, p. 235-260, jan./jun. 2012 
entourage) o que torna possível essa distribuição (p. 203). ${ }^{32}$ Se a feitiçaria é um sistema de lugares, cada um desses lugares não é senão a expressão de um nome, por cuja mediação o lugar do enfeitiçado ganha a forma de um contínuo (p. 334). E é exatamente aí que se manifesta, de maneira mais evidente, a discrepância entre a ontologia médica e a ontologia da feitiçaria, além, é claro, daquela entre as suas respectivas epistemologias. A ontologia do evento-feitiçaria como repetição de infortúnios supõe esse duplo movimento por meio do qual, ao mesmo tempo, se forma um contínuo entre homens, animais e objetos materiais e se instaura uma descontinuidade entre a origem e a causa do que acontece. ${ }^{33}$ À medida que as séries se conectam, o sentido se separa. ${ }^{34}$

"Pour que ça se répète ainsi, il faut bien supposer quelque part un sujet qui le désire” (p. 23). ${ }^{35}$ Em face do que o anunciador perguntará ao enfeitiçado: haverá alguém que lhe queira o mal? Quando se pergunta sobre o "quem das coisas”, é certo que já se está no domínio do evento-feitiçaria. O problema, a partir de agora, é encontrar um nome, e não um diagnóstico.

Um nome, mas antes disso será preciso examinar o que leva o feiticeiro a atacar alguém, a razão que faz dele um ser agressivo e "invejoso". Diferentemente do nome, que individualiza a relação do feiticeiro com o enfeitiçado, permitindo estabelecer uma relação direta entre eles, a razão diz respeito ao funcionamento geral do sistema da feitiçaria, ou melhor, aos seus pressupostos de base. Digamos então que o feiticeiro ataca porque

$32 \mathrm{O}$ evento-feitiçaria atualiza essa dimensão distribuída que define virtualmente a pessoa. "Il est, en effet, remarquable que les Bocains utilisent deux conceptions distinctes du rapport d'un sujet à son espace social, selon que la sorcellerie est ou non en question dans une situation donnée.” "“Com efeito, é notável que os habitantes do Bocage utilizem, conforme a feitiçaria esteja ou não em questão em uma determinada situação, duas concepções diferentes da relação entre uma pessoa e o seu espaço social.”) (p. 218). Relação com o espaço social que, como se pode ver, também parece ser uma singular relação consigo mesmo.

${ }^{33} \mathrm{O}$ momento crítico é esse quando se passa da série animal para a humana (p. 249). “[...] la répétition du malheur biologique comprise comme une scansion, pour chacun, de sa propre mort” ("a repetição do infortúnio biológico compreende, para cada pessoa, uma escansão de sua própria morte”) (p. 213). Essa frase condensa a violência do que está em jogo: para cada enfeitiçado, a repetição é como a métrica de sua própria morte.

${ }^{34}$ Em contrapartida, no cotidiano, que parece se definir como o tempo em que não se está sob o ataque da feitiçaria, o que predomina é a descontinuidade. "Julian Monnier, par exemple, dirait alors simplement que sa femme est malade et non qu'il est ensorcelé; ou bien, s'il a lui-même la diarrhée, qu'il est malade et non pas ensorcelé." (“Julian Monnier, por exemplo, diria então simplesmente que sua mulher está doente e não que ele está enfeitiçado, ou então, se ele próprio estiver com diarreia, que ele está doente e não enfeitiçado.”) (p. 219, grifo da autora).

35 “Para que isso se repita dessa maneira, é necessário supor, em algum lugar, uma pessoa que o deseje.”

Horizontes Antropológicos, Porto Alegre, ano 18, n. 37, p. 235-260, jan./jun. 2012 
simplesmente não tem a escolha de não atacar. Para ele, a guerra não é uma opção.

Dizia antes que nesse sistema de lugares que é a feitiçaria, não há lugar para o que não tem lugar. Com efeito, todos os espaços vitais encontram-se marcados por esse limite que é o nome de um chefe de família, e não há possibilidade de que algum deles esteja vazio. O nome é o que territorializa o lugar, circunscrevendo a fronteira de seu domínio. Mas Favret-Saada sugere que essa dimensão topológica coexista com uma outra de natureza dinâmica. Nesse caso, o domínio, além de sua territorialidade mais restritiva, define-se também como a expressão da força (vital) de quem o possui. ${ }^{36}$ Distinguem-se então duas possibilidades: aquela de uma pessoa comum, e uma outra, associada àqueles indivíduos (o feiticeiro e o desenfeitiçador) que possuem força mágica (p. 336).

Na primeira situação, o nome é capaz de conter a força. "On peut dire que, dans ce cas, la force, le nom et le périmètre du domaine se recouvrent exactement. Les échanges qu'instituent entre eux des possesseurs quelconques maintiennent cette force (ce potentiel bio-éonomique) à un niveau constant...” (p. 339). ${ }^{37} \mathrm{Na}$ segunda, a força é incontida pelo nome. Nesse caso, só resta ao feiticeiro lançar-se sobre um outro lugar, o qual, invariavelmente, pertence a um indivíduo que, não possuindo força mágica, será sempre mais fraco do que ele, não tendo assim quaisquer meios para se defender. É o desenfeitiçador quem o proverá de tais meios, e se ele aceita fazê-lo não é somente porque o enfeitiçado esteja lhe pagando, mas sim porque, da mesma forma que $\mathrm{o}$ feiticeiro, ele deve direcionar a sua força excedente para alguém. ${ }^{38}$

36 A “força vital” é o que se chama no livro de “potencial bioeconômico” de cada domínio, isto é, as suas capacidades de sobrevivência (válida para as pessoas e os animais), reprodução (idem ao primeiro) e produção. A expressão dessa força está diretamente vinculada ao nome do chefe de família, e é a ela, a esse seu potencial bioeconômico, que visa o feiticeiro por ocasião do seu ataque a esse chefe (p. 335).

37 “As trocas que os proprietários realizam entre si, quaisquer que sejam eles, mantêm essa força (esse potencial bioeconômico) em um nível constante...”

38 “S’il y a peu de doute que le désorceleur trouve là une jouissance immense qui, à mon sens, constitue son paiement réel - l'argent échangé venant simplement inscrire cette jouissance dans des médiations symboliques acceptables -, il reste que d'occuper cette place de volontaire de la mort suppose un courage et une force extrêmes.” (“Se há pouca dúvida quanto ao fato de o desenfeitiçador encontrar aqui uma profunda alegria, a qual, do meu ponto de vista, constitui o seu pagamento real - o pagamento em dinheiro sendo apenas a inscrição dessa alegria nas mediações simbólicas aceitáveis - resta que, para ele, ocupar este lugar de voluntário para a morte supõe uma coragem e uma força extremas.”) (p. 271). Mas é provável que também suponha uma impossibilidade de não fazer a guerra, de resto parecida, ainda que não igual, à do feiticeiro. Ambos participam, embora cada um a seu modo, daquele ser-para-a-morte que Pierre Clastres (2004, p. 304) descreveu como “o infortúnio do guerreiro selvagem”.

Horizontes Antropológicos, Porto Alegre, ano 18, n. 37, p. 235-260, jan./jun. 2012 
Menos do que sobre um lugar, o desenfeitiçador fará essa força incidir sobre uma outra força, a do feiticeiro, como se ele, paradoxalmente, precisasse do ataque desse último para poder canalizar a força que excede ao seu próprio lugar. Ambos, feiticeiro e desenfeitiçador, vivem da guerra, mas não da mesma maneira: a guerra do segundo só pode ser a guerra que tenha como alvo a própria guerra perpetrada pelo primeiro contra o enfeitiçado. Como se esse campo de batalha que é o evento-feitiçaria fosse necessário ao desenfeitiçador para que ele não viesse a correr o risco de se tornar um feiticeiro. Pois, do contrário, para qual lugar ele direcionaria a sua força?

A condição para que o feiticeiro mantenha a sua força vital é que faça avançar a sua força mágica sobre a força vital de uma outra pessoa (p. 353). Ele precisa arriscar a perder a primeira (já que quase inevitavelmente irá se confrontar com a força de um poderoso desenfeitiçador) porque é compelido a fazê-lo pela segunda, ou melhor, porque é tido por ela, porque "elle le possède et le contraint à un travail incessant comparable à celui de l'esclave” (p. 344). ${ }^{39}$ É certo que ele a tem, mas não é menos certo que ela, por sua vez, jamais deixa de tê-lo. "Il serait donc plus correct de dire que cette force excédentaire et nécessairement illimitée passe par le corps/le nom/le domaine du sorcier.” (p. 344). ${ }^{40}$ Soma-se à indisponibilidade de espaço, a força incontida de um lugar (p. 131). A guerra não é aquilo que o feiticeiro quer, mas o que quer nele, ou através dele. Eis o que se poderia definir como a assimetria ontológica desse sistema: nenhum lugar está vazio, mas um deles está sempre cheio demais.

O que está em jogo é a coexistência de duas possibilidades de troca: uma, que poderíamos chamar de simétrica, porque mantém constante a circulação da força vital, e outra, por óbvio assimétrica, já que pressupõe que alguém deve perder essa mesma força. O fato é que não há lugar para dois: ou é o enfeitiçado (aliado com o desenfeitiçador), ou é o feiticeiro. Digamos, portanto, que há feitiçaria quando uma pessoa deve necessariamente perder, ou seja, morrer. E mesmo que ela não morra, ainda assim o que está em jogo é sempre a sua morte. No evento-feitiçaria, o que circula é a força vital, só se pode perdê-la ou ganhá-la, e o que a faz circular, o que torna possível que alguém

39 “Ela o possui e o constrange a um trabalho incessante comparável àquele do escravo.” Àquele feiticeiro que se encontra na iminência de ser derrotado só resta a alternativa de deslocar a aplicação de sua força para o lugar de uma outra pessoa.

40 "Seria portanto correto dizer que esta força excedente e necessariamente ilimitada passa pelo corpo, pelo nome, pelo domínio do feiticeiro.” 
a perca ou a ganhe, é a força mágica (p. 125). Em outras palavras, o eventofeitiçaria é a assimetrização da forma-troca pela força mágica.

Há mais, contudo. O evento-feitiçaria, entendido como assimetrização da troca, supõe ainda a comutabilidade das posições de quem troca. É isso o que vemos, por exemplo, na relação entre o enfeitiçado Manceau e o seu feiticeiro Tripier. Como seria impossível retomá-la aqui na complexidade dos seus detalhes, limitarei o meu comentário ao seu desfecho. ${ }^{41}$ Será suficiente notar que o primeiro, acusando o segundo de tê-lo enfeitiçado, alia-se ao desenfeitiçador Grippon, os quais, procedendo de acordo com o ritual apropriado à circunstância (p. 122), derrotam Tripier, enviando-o em estado grave para o hospital, onde lhe é amputada uma parte do intestino. Manceau então está curado. Mas é aqui que o sistema mostra a complexidade do seu funcionamento, pois o evento-feitiçaria não acaba depois que terminam os seus efeitos sobre alguém. Pelo contrário, ele entra em uma nova repetição, não mais a dos infortúnios de Manceau, e sim aquela dos infortúnios de Tripier.

O feiticeiro que se dizia não feiticeiro passa então a se dizer enfeitiçado por aquele que, no entanto, viu no que fez apenas um desenfeitiçamento. Manceau devolveu a Tripier o feitiço que este último tinha jogado sobre ele. Mas o que era para Manceau um desenfeitiçamento, torna-se para Tripier, que nunca enfeitiçou ninguém, um enfeitiçamento. Ao que parece, qualquer eventofeitiçaria é, no mínimo, dois, mas para isso é necessário que existam, pelo menos, três posições. O desenfeitiçador é o "transformador lógico" (p. 357) que torna possível que o desenfeitiçamento do enfeitiçado se transforme em enfeitiçamento do feiticeiro. O que ocorre quando Grippon desenfeitiça Manceau agindo contra Tripier não será exatamente a mesma coisa se estivermos do lado de Tripier (p. 129, 130). Como se vê, a equivocação (Viveiros de Castro, 2004) é a duplicação imanente a cada evento-feitiçaria. ${ }^{42}$ Justamente por isso,

${ }^{41}$ Essa é uma das histórias mais detalhadamente narradas no livro. A outra é a do enfeitiçado Jean Babin, que ocupa praticamente toda a terceira e última parte da obra, intitulada "Tout dire". Ainda que não da mesma maneira, podemos encontrar, em ambas, essa comutabilidade das posições. Sobre a primeira, ver p. 121-133, sobre a segunda, p. 315-329.

42 "Equivocação" remete aqui à ideia da diferença, ou da não coincidência, como algo imanente ao mundo. A feitiçaria é aquilo que todos compartilham, mas, nesse caso, não se trata da mesma coisa para cada um deles. O problema é sempre o de saber de qual lado é que se está, o que inclui o lado do outro como interno a ele, pois, na descrição proposta por Jeanne Favret-Saada, os lugares que compõem o sistema da feitiçaria não são necessariamente idênticos a si próprios. Ver ainda sobre a equivocação, ou sobre "o equívoco como categoria fundamental da antropologia”, Viveiros de Castro e Sztutman, (2008, p. 104, 106,107 , grifo dos autores).

Horizontes Antropológicos, Porto Alegre, ano 18, n. 37, p. 235-260, jan./jun. 2012 
o que se troca, nessa troca assimétrica, são as próprias posições de enfeitiçado e de feiticeiro e, assim, o sentido a respeito desse acontecimento perspectivo que é o evento-feitiçaria. Se a repetição do infortúnio pode terminar para alguém é porque tende infinitamente a ser retomada por outrem.

O desenfeitiçador é o "transformador lógico", porém, o lugar da equivocação que torna possível essa transformação é aquele que ninguém quer ocupar: o lugar do feiticeiro. De fato, é preciso que ninguém se disponha a ocupá-lo para que qualquer um possa ocupá-lo. De outro modo, é porque ninguém se identifica como pertencente a esse lugar que ele pode produzir um efeito generalizado de diferenciação. Trata-se do lugar graças ao qual nenhum lugar pode coincidir inteiramente consigo mesmo.

“Situation typique [...] où l'ensorcelé se dit tel à la suite d'une accusation de sorcellerie.” (p. 310). ${ }^{43}$ Mas se o enfeitiçado Jean Babin não era de fato o feiticeiro de seus vizinhos, tal como eles diziam, como é possível que o desenfeitiçamento desses últimos tenha atingido-o tão profundamente, levandoo a se tornar um alcoólatra (p. 318, 319)? Ele sabia que não era o feiticeiro, mais quand même... O feiticeiro é ele, mas ele, eventualmente, pode ser eu, ainda que, para mim, jamais eu possa ser. O pronome é o virtual imanente a cada nome.

A esse sistema de lugares estriado pelos nomes, o lugar do feiticeiro, que tende a existir como pronome, sobrepõe intensivamente um espaço liso (Deleuze; Guattari, 1997). O feiticeiro é aquele que, mesmo possuindo o seu próprio lugar, é forçado a ocupar o lugar de um outro, desfazendo, ainda que provisoriamente, os limites existentes entre esses lugares. Vemos assim o sistema de nomes desterritorializar-se sobre a força dêitica, ou o fluxo contínuo, de um pronome.

Se o evento-feitiçaria está associado a uma força que não pode ser contida pelo sistema dos nomes, é possível que a nominação do feiticeiro seja uma primeira tentativa para dar forma àquilo que, por si só, escapa à enformação (p. 132). Contudo, há sempre algo que, no próprio nome do feiticeiro, desenha uma fuga sobre a difícil e frágil tarefa de sua nominação. É esse algo que põe a questão: “Celui qu’on a vu là, ‘tout électrique’ et qui fait peur,

43 “Situação típica [...] na qual o enfeitiçado se apresenta como tal na sequência de uma acusação de feitiçaria.”

Horizontes Antropológicos, Porto Alegre, ano 18, n. 37, p. 235-260, jan./jun. 2012 
est-ce bien Tripier, n'est-ce pas plutôt l'innommable ou, ce qui revient au même, l'incomparable, ce dont nul n'a jamais pris la mesure?” (p. 131, grifo da autora). ${ }^{44}$ Para além do rosto familiar de Tripier, perfila-se essa força estranha, anônima, que o possui (p. 131).

Como um lugar definido por um outro, o lugar do feiticeiro visa sempre a ocupar o lugar desse outro, antes do qual, no entanto, ele não existia. Só se pode colocar alguém aí, supondo que não caiba inteiramente aí. Sai-se do pronome na direção daquilo que escapa ao nome. Como se vê, o nome do feiticeiro é o intervalo entre o lugar que ele se recusa a ocupar e o excesso que um outro, à revelia de sua recusa, designa como o modo de sua ocupação.

Significativamente, em um sistema no qual não há lugar vazio, o do feiticeiro é aquele que todos se recusam a ocupar. Situação agravada pelo fato de que o feiticeiro é tido por um hipócrita, alguém que "esconde a sua própria natureza”, logo, o que se espera dele é que diga que não é um feiticeiro (p. 226). ${ }^{45}$ Vê-se o drama de todo aquele que, acusado de feitiçaria, considera-se a si mesmo como inocente (p. 283): se ele disser que não é feiticeiro, é porque é; se nada disser, algo de ruim poderá lhe acontecer, já que desenfeitiçar é simplesmente inverter a assimetria inicial provocada pelo feiticeiro, algo como enfeitiçar às avessas (p. 273). Foi o que aconteceu com Jean Babin, que, após o desenfeitiçamento daquele que o acusou, tornou-se alcoólatra, isto é, enfeitiçado.

Se falar sobre a feitiçaria envolve sérios riscos, na relação entre o enfeitiçado e o seu desenfeitiçador conta o preceito de "tudo dizer" ("tout dire"), pois é tudo dizendo sobre o que tem acontecido que se poderá identificar o feiticeiro (p. 272). Que o enfeitiçado tenha sido, ele próprio, acusado de feitiçaria, é isso, contudo, o que ele jamais poderá dizer ao desenfeitiçador, dado que, se assim o fizesse, tornaria impossível a sua transformação de feiticeiro em enfeitiçado. Deve-se dizer tudo, menos o que não se deve. E isso que não se deve, não é, como disse mais atrás, o que se oculta, mas, simplesmente,

\footnotetext{
44 “Aquele que se vê ali, todo eletrizado e que provoca medo, é mesmo Tripier, ou será, sobretudo, o inominável, ou ainda, o que vem a dar no mesmo, o incomparável, aquele que escapa de toda medida?”

45 “Ses victimes [do feiticeiro] assurent qu'il n’a pas besoin de s'avouer sorcier, parce que sa mort parle pour lui..." ("Suas vítimas asseguram que ele não tem necessidade de se assumir como feiticeiro, pois sua morte fala por ele...”) (p. 50). Nesse sistema, não é casual que a morte do feiticeiro seja a sua única identificação como feiticeiro. Sendo sempre outro, o feiticeiro é falado pela sua morte, essa sua "morte ventríloqua” (Viveiros de Castro, 2002a).
} 
o que não há para ser dito. Creio que se possa chamá-lo de silêncio. Fala-se tudo o que se pode falar, e o silêncio é parte disso, mas não como aquilo que esconde o que não se diz no que se diz, e sim como a condição imanente ao próprio dizer, como se o silêncio fosse o lugar do feiticeiro virtualmente contido em todos os lugares.

A feitiçaria é apenas fala, mas o que faz falar é o silêncio que a própria fala infinitamente repõe; é um sistema de lugares, mas um deles está vazio por estar simultaneamente muito cheio; é um sistema de nomes, mas é um pronome que o faz existir. Sugiro, para concluir por uma volta ao começo, que esse silêncio, esse lugar e esse pronome sejam "comme une force anonyme, comme un 'ça' venu on ne sait d'où”46 (p. 311). O sistema que talvez parecesse ser feito somente de formas (lugares, nomes, limites...) tem o seu sentido escoado por essa força que o percorre, simultaneamente constituindo e vazando o seu interior. Sem nome e sem lugar, essa força é o que se diz como um dêitico: isso. "Entre nós, só se conhece isso: a morte." ${ }^{47} \mathrm{O}$ quem das coisas tem forma, e também não tem. Les mots, la mort, les sorts é o testemunho de como se vive quando se vive assim, é a experiência dessa experiência.

\section{Referências}

BARBOSA NETO, E. R. A máquina do mundo: variações sobre o politeísmo em coletivos afro-brasileiros. Tese (Doutorado em Antropologia Social)Museu Nacional/Universidade Federal do Rio de Janeiro, Rio de Janeiro, 2012.

BARTHES, R. Inéditos (vol.2): crítica. São Paulo: Martins Fontes, 2004.

BENVENISTE, É. Problemas de lingüística geral I. Campinas: Pontes, 1988.

CLASTRES, P. Arqueologia da violência: pesquisas de antropologia política. São Paulo: Cosac \& Naify, 2004.

\footnotetext{
46 “Como uma força anônima, como um ‘isso’ vindo sabe-se lá de onde.”

47 Era o que dizia Jean Lenain, o desenfeitiçador dos Fourmond, para a etnógrafa: "Ici, on est tout de suite pris à mort; la mort, on ne connaît que ça, chez nous.” (“Aqui, é-se logo tomado pela morte; entre nós, só se conhece isso: a morte.”) (p. 128).
} 
DE CERTEAU, M. A invenção do cotidiano. Petrópolis: Vozes, 2005.

DE CERTEAU, M. A linguagem alterada: a palavra da possuída. In: DE CERTEAU, M. A escrita da história. Rio de Janeiro: Forense Universitária, 2006. p. 219-241.

DELEUZE, G. A literatura e a vida. In: DELEUZE, G. Crítica e clínica. São Paulo: Editora 34, 1997.

DELEUZE, G.; GUATTARI, F. Mil platôs: capitalismo e esquizofrenia. São Paulo: Editora 34, 1997. v. 5.

ECO, U. Kant e o ornitorrinco. Rio de Janeiro: Record, 1998.

EVANS-PRITCHARD, E. Bruxaria, oráculos e magia entre os Azande. Rio de Janeiro: Jorge Zahar, 2005.

FAVRET-SAADA, J. les mots, la mort, les sorts. Paris: Gallimard, 1977.

FAVRET-SAADA, J. Ser afetado (tradução de Paula de Siqueira Lopes). Cadernos de Campo, n. 13, p. 155-161, 2005.

GELL, A. Art and agency: an anthropological theory. Oxford: Clarendon Press, 1998.

GOLDMAN, M. Jeanne Favret-Saada, os afetos, a etnografia. Cadernos de Campo, n. 13, p. 149-153, 2005.

GOLDMAN, M. Como funciona a democracia: uma teoria etnográfica da política. Rio de Janeiro: 7 Letras, 2006.

GOLDMAN, M.; VIVEIROS DE CASTRO, E. Abaeté, rede de antropologia simétrica. Cadernos de Campo, n. 14/15, p. 177-190, 2006. (Entrevista concedida a Aristóteles Barcelos Neto, Danilo Ramos, Maíra Santi Bühler, Renato Sztutman, Stelio Marras e Valéria Macedo).

LATOUR, B. Petite réflexion sur le culte moderne des dieux faitiches. Paris: Synthélabo, 1996. 
LEIRIS, M. A África fantasma. São Paulo: Cosac \& Naify, 2007.

MANNONI, O. “Eu sei, mas mesmo assim...” In: KATZ, C. (Org.). Psicose: uma leitura psicanalítica. São Paulo: Editora Escuta, 1991.

MAUSS, M.; HUBERT, H. Esboço de uma teoria geral da magia. In: MAUSS, M. Sociologia e antropologia. São Paulo: Cosac \& Naify, 2003. p. 47-181.

VELHO, O. O que a religião pode fazer pelas ciências sociais? In: TEIXEIRA,F. (Org.). A(s) ciência(s) da religião no Brasil: afirmação de uma área acadêmica. São Paulo: Paulinas, 2001. p. 233-250.

VIVEIROS DE CASTRO, E. A inconstância da alma selvagem - e outros ensaios de antropologia. São Paulo: Cosac \& Naify, 2002a.

VIVEIROS DE CASTRO, E. O nativo relativo. Mana, v. 8, n. 1, p. 113-148, 2002b.

VIVEIROS DE CASTRO, E. Perspectival anthropology and the method of controlled equivocation. Tipití, v. 2, n.1, p. 3-22, 2004.

VIVEIROS DE CASTRO, E.; SZTUTMAN, R. Encontros: Eduardo Viveiros de Castro. Rio de Janeiro: Azougue Editorial, 2008.

WAGNER, R. A invenção da cultura. São Paulo: Cosac \& Naify, 2010. 